IRA-International Journal of Applied Sciences ISSN 2455-4499; Vol.04, Issue 01 (2016)

Institute of Research Advances

http://research-advances.org/index.php/IRAJAS

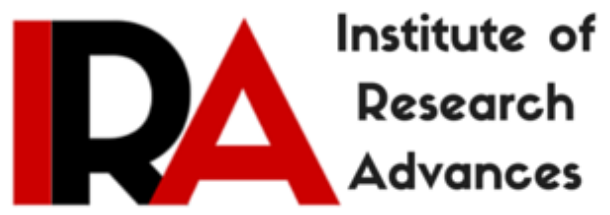

\title{
Angina Bullosa Haemmorhagica on the Ventral Surface of the Tongue- a rare case report
}

\author{
Karthik.R ${ }^{1}$, Mohan $\mathbf{N}^{2}$, Ravikumar. P.T $\mathbf{T}^{3}$ \\ ${ }^{1,3}$ Reader,Department of Oral Medicine and Radiology,Vinayaka Missions \\ Sankarachariyar Dental College, Salem, India. \\ 2 Professor and Head of Department,Department of Oral Medicine,Diagnosis and \\ Radiology,Vinayaka Missions Sankarachariyar Dental College, Salem, India.
}

DOI: $\underline{\text { http://dx.doi.org/10.21013/jas.v4.n1.p14 }}$

\section{How to cite this paper:}

R, K., N., M., \& P.T, R. (2016). Angina Bullosa Haemmorhagica on the Ventral Surface of the Tongue- a rare case report. IRA-International Journal of Applied Sciences (ISSN 2455-4499), 4(1). doi:http://dx.doi.org/10.21013/jas.v4.n1.p14

(C) Institute of Research Advances (cc) EY-NC

This works is licensed under a Creative Commons Attribution-Non Commercial 4.0 International License subject to proper citation to the publication source of the work.

Disclaimer: The scholarly papers as reviewed and published by the Institute of Research Advances (IRA) are the views and opinions of their respective authors and are not the views or opinions of the IRA. The IRA disclaims of any harm or loss caused due to the published content to any party. 


\section{ABSTRACT}

Angina Bullosa Hemmorhagica is a condition affecting the oral mucous membrane characterised by the presence of oral subepithelial blood filled blisters that ruptures and heals spontaneously by itself without any scarring.

Key words : Blood filled Blisters, Trauma,ventral surface of tongue.

Patient named shadasivam of age 68 / $\mathrm{M}$ came to our department of oral medicine and radiology,Vinayaka missions sankarachariyar Dental college with a chief complaint of missing teeth .He was refererred to the Department of Prosthodontics.After 1 week the Patient reported back to the Department of oral Medicine and Radiology with a complaint of Blood tinged saliva. On eliciting his Personal Habits, he was a non smoker and non alcoholic. His family history was unremarkable.Medical History reveals that he is a Known Diabetic and Hypertensive and under Medication. He gives no history of any drug allergy. Intraoral examination revealed the presence of two intact bullae near the left side of the ventral surface of the tongue. On the right side ventral surface of the tongue, patient presents with ruptured bullae. On eliciting the history of present illness, patient gives history of trauma near the ventral surface of the tongue while doing a border molding procedure for the fabrication of mandibular complete denture. Correlating the history of trauma ,clinical Features and the chief complaint, a provisional diagnosis of Angina Bullosa Hemmorhagica was made.

\section{INTRAORAL EXAMINATION}

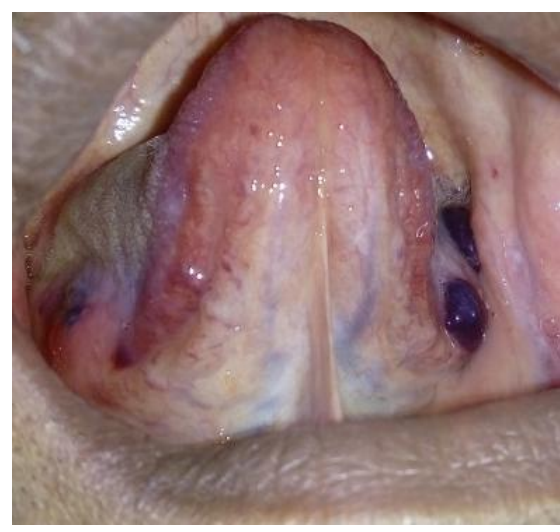

FOLLOW UP AFTER 7 DAYS

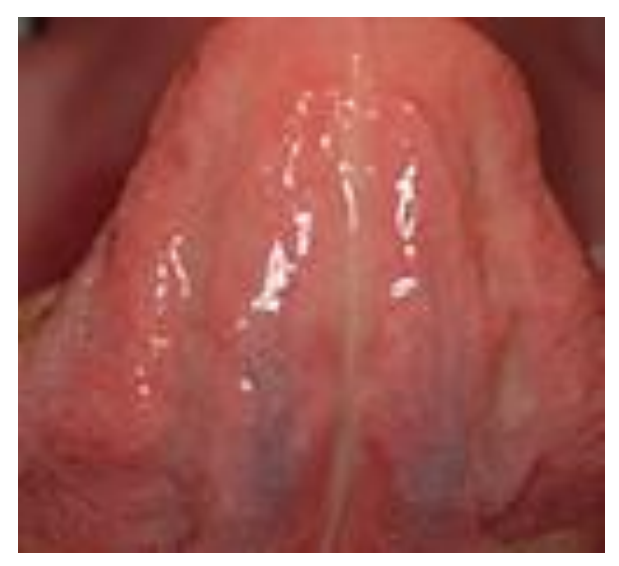




\section{DISCUSSION}

Angina bullosa hemorrhagic (ABH) describes the acute and sometimes painful onset of oral bloodfilled vesicles and bullae, not attributable to blood dyscrasia, vesiculobullous disorders, systemic diseases or other known causes. The haemorrhagic bullae spontaneously burst after a short time resulting in ragged, often painless, superficial erosions that heal spontaneously within 1 week without scarring. Trauma appears to be the most common identifiable precipitating factor.

This condition was first described in 1933 by Balina of Argentina_ as traumatic oral haemophlyctenosis. He also postulated a trauma-induced origin, especially in patients with senile capillary changes and Badham_in 1967 first used the currently accepted term ABH. This entity was then named recurrent oral hemophlyctenosis $(\mathrm{ROH})$. As Kirtschig and Happle pointed out, the term $\mathrm{ABH}$ is misleading because most bullae arise in the oral cavity and are not consistent with lesions usually called 'angina'; they proposed a more appropriate name for the disease: stomatopompholyx haemorrhagica. The authors believe that Balina was the first to describe this condition and suggested the use of the name $\mathrm{ROH}^{1}$

The awareness of $\mathrm{ABH}$ in the field of dermatology and dentistry is very much necessary to avoid misdiagnosis, since this condition spontaneously rupture and heal without any treatment. This case report creates awareness regarding occurrence of the lesion especially on ventral surface of the tongue.

Routine blood examination, which included platelet count, bleeding time, clotting time, prothrombin time, WBC count and blood sugar random were within normal limits.

The lesion persisted for few hours and then spontaneously ruptured and eventually healed in next 2 days.

The described cases of angina bullosa hemorrhagica $(\mathrm{ABH})$ had spontaneous onset or were related to minor trauma of ingestion of hot drinks, hard, rough, and crispy food, trauma from sharp edges of adjacent attrited teeth, Smokeless Tobacco,coughing, sneezing, shouting, restorative dentistry such as Metal crowns and Prosthesis or periodontal therapy ${ }^{2}$.

Garlick JA reported a case of Angina Bullosa Hemmorhagica ( $\mathrm{ABH}$ ) following secondary to trauma of eating and dental injection ${ }^{3}$

Hosain and colleagues reported a case of postoperative ABH caused by intubation and extubation, describing a patient with a single blister at the junction of the soft and hard palate that did not compromise the patient's airway. ${ }^{4}$

High AS et al reported a case of angina bullosa haemmorhagica as a complication of long term steroid inhaler use. ${ }^{5}$

Pahl $\mathrm{C}$ et al reported a case of angina bullosa haemorrhagica occurring in the oropharynx in the posterior Pharyngeal wall obstructing the airway , requiring tracheal intubation ${ }^{6}$

Diabetes mellitus may be a contributing factor in developing ABH. Some authors suggest mild trauma as the causative agent in $\mathrm{ABH}$ to break the epithelial-connective-tissue junction, causing bleeding of superficial capillaries and resulting in the formation of a subepithelial hemorrhagic bullae.

The blister of angina bullosa hemorrhagica $(\mathrm{ABH})$ appears tense, dark red to purple in color, and blood-filled surrounded by an ecchymotic halo. It has an average size of 1-3 cm in diameter.

The soft palate is the most commonly affected site in angina bullosa hemorrhagica. Occasional lesions have been reported in the buccal mucosa, alveolar ridge, tongue, hard palate, and, rarely, the gingiva. If located on the tongue, the Lateral borders of the tongue which are frequent sites of trauma is most commonly affected. The vermillion border of the lips are almost always spared.-Angina bullosa hemorrhagica also may involve the pharynx and the esophagus. -Approximately one third of the patients exhibit lesions in more than one location. 
Grinspan et al reported that 44\% of his patients in a series of 24 cases published in 1999 had from type II diabetes, hyperglycemia, or family history of diabetes. No conclusive evidence of a cause-and-effect relationship exists between the presence of angina bullosa hemorrhagica and glucose metabolism. ${ }^{7}$

Stephenson published a large series of 30 patients, not finding a clear precipitating factor in $47 \%$ of the cases.There have been many precipitating factors described: trauma by a sharp cusp or edge of an adjacent tooth or metal crown, masticatory trauma, hot drinks, use of steroids, as well as dental or injection of local anesthesia prior to extraction of teeth or vital crown preparation or root canal treatment. ${ }^{8}$

One case of Angina Bullosa Hemmorhagica was reported in a 50 year old chronic renal failure Patient since two years who was on Hemodialysis for 8 months with Hypertension. ${ }^{9}$

Differential diagnosis must include pemphigus, bullous pemphigoid, bullous lichen planus, dermatitis herpetiformis, Erythema Multiforme and thrombocytopenia.

In Pemphigus the Bullae are not Blood filled whereas in ABH the Bullae are Blood filled.

Bullous pemphigoid is differentiated from $\mathrm{ABH}$ in that the Bullae of Bullous pemphigoid is tense or thick walled and not easily rupturable whereas in Angina Bullosa Hemmorhagica, the Bullae are easily rupturable. Characteristic Ocular signs such as Entropion( inwardly placed eyelashes ) ,Trichiasis (inwardly placed eye lashes injuring the cornea) and Symblepharon

( fibrous adhesions between the palpebral conjunctiva and the sclera of the eyeball restricting the movements of the eyeball ) can be seen in Cicatrial Pemphigoid (Cicatricial - refers to scarring). No such ocular signs occurs in Angina Bullosa Hemmorhagica (ABH).

In Erthema Multiforme there is characteristic Presence of Haemmorhagic crusting on the Vermilon Border of Lips whereas Vermilon Border of lip is not involved in ABH. Thrombocytopenia is a blood dyscrasia where there is reduction in the number of platelets that results in bleeding from all the orifices of the body (Epistaxis -Bleeding from Nose,Blood in urine and stools ,Bleeding from Gingiva). Superficial bleeding into the skin that appears as a rash of pinpoint-sized reddish-purple spots (petechiae), usually on the lower legs. No treatment is required for $\mathrm{ABH}$ because the blood blisters spontaneously rupture and heal.RAS gel (20\% Benzocaine Local anesthetic gel ) provided symptomatic relief.Patient was recalled after 7 days.Healing Appears satisfactory.

\section{CONCLUSION}

Most of the general practitioners are unaware of this lesion leading to misdiagnosis and patient is subjected to unnecessary treatment since this condition spontaneously rupture and heal without any treatment. This case report creates awareness regarding occurrence of the lesion especially on the ventral surface of the tongue.Patient affected with $\mathrm{ABH}$ have blood tinged saliva that can be mistaken as carcinoma by them.

\section{REFERENCES :}

1.Dipti Singh, Neeta Misra,Sudhanshu Agrawal, and Pradyumna Misra, Angina Bullosa Haemmorhagica,_BMJ Case Rep. 2013; 2013: bcr2012008505.

2.Curran AE, Rives RW. Angina bullosa haemorrhagica: an unusual problem following periodontal therapy. J Periodontol 2000;71:1770-3

3.Garlick JA, Calderon S. Oral blood blisters in angina bullosa haemorrhagica secondary to trauma of eating and dental injection. Br Dent J. 1988;165:286-7.

4.Hosain SI, Bounds G, Stanford J. Angina bullosa haemorrhagica causing respiratory obstruction postoperatively.Anaesthesia1991;46: 422

5.High AS, Main DMG. Angina bullosa haemorrhagica: a complication of long-term steroid inhaler use.Br Dent J1988;165: 176-9 
6.Pahl C, Yarrow S, Steventon N, et al. Angina bullosa haemorrhagica presenting as acute upper airway obstruction. Br J Anaesth 2004;92:283-6

7.Grinspan D, Abulafia J, Lanfranchi H.Angina bullosa hemorrhagica. Int J Dermatol 1999;38:525-8. 8.Stephenson P, Lamey PJ, Scully C, PrimeSS. Angina bullosa haemorrhagica: clinical and laboratory features of 30 patients. Oral Surg Oral Med Oral Pathol 1987;63:560-5.

9.Shashikumar BM, R Raghunatha Reddy, and MR Harish, Oral Haemmorhagic Blister,an Enigma, Indian J Dermatol. 2013 Sep-Oct; 58(5): 407. 